\title{
FORMULATION AND EVALUATION OF GASTRO-RETENTIVE DRUG DELIVERY SYSTEM CONTAINING COMBINATION OF GLIPIZIDE AND METFORMIN HYDROCHLORIDE
}

\author{
SHAJAN ABRAHAM ${ }^{1}$, MUHAMMED NAUFAL ${ }^{2}$, VIDYA PETER ${ }^{1 *}$, SUSAN RAJU ${ }^{1}$, CHRISTINA DAS $^{1}$ \\ ${ }^{1}$ Department of Pharmaceutics, Nazareth College of Pharmacy, Othera, Kerala, India, ${ }^{2}$ Department of Pharmaceutics, Sheedevi College of \\ Pharmacy, Mangaluru, Karnataka, India. Email: vidyapeter1990@gmail.com
}

Received: 25 July 2016, Revised and Accepted: 29 July 2016

\section{ABSTRACT}

Objective: Is to develop a gastroretentive drug delivery system of glipizide and metformin hydrochloride is to overcome the biggest problem in oral drug delivery is low and erratic drug bioavailability.

Methods: Seven formulations containing retardant material and alkalizing agent were prepared with solubilizing agent in different ratios. The ability of various polymers to retain the drug when used in different concentrations was investigated. It was found that sodium bicarbonate reacts with $\mathrm{HCl}$ and produce $\mathrm{CO}_{2}$ which creates pores in tablet and elevates swelling by wetting polymer. Hence, it helps in maintaining the buoyancy. The release rate could be modified by varying the polymer ratio, concentration of alkalizing, and solubilizing agent. The prepared tablets were evaluated for general appearance, content uniformity, hardness, friability, buoyancy, and in vitro dissolution studies.

Results: The in vitro drug release profiles obtained for tablets (F2) made with combinations of hydroxypropyl methylcellulose (HPMC) K4M, HPMC, and K100M showed lesser floating lag time ( $<60$ seconds) and a prolonged floating duration ( $>14 \mathrm{hrs}$ ) with controlled and sustained release of MHCl and GD.

Conclusion: Controlled release floating drug delivery of GD and $\mathrm{MHCl}$ showed sufficient release for an extended period of time. As a result, the frequent dosing and possible incomplete absorption of drug can be avoided.

Keywords: Controlled drug release, Gastro-retentive drug delivery system, Metformin hydrochloride, Glipizide.

(C) 2016 The Authors. Published by Innovare Academic Sciences Pvt Ltd. This is an open access article under the CC BY license (http://creativecommons. org/licenses/by/4. 0/) DOI: http://dx.doi.org/10.22159/ajpcr.2016.v9i6.14286

\section{INTRODUCTION}

Gastroretentive dosage forms are a variable process and it as ability to prolong and control emptying time is a valuable asset for dosage forms, which reside in the stomach for a longer period of time than conventional dosage forms. Gastroretensive systems can remain in the gastric region for several hours and hence significantly prolong the gastric residence time of drugs. Prolonged gastric retention improves bioavailability, reduces drug waste, and improves solubility for drugs that are less soluble in a high $\mathrm{pH}$ environment [1-5].

Metformin $\mathrm{HCl}$ and glipizide is an anti-diabetic drug. Glipizide and metformin $\mathrm{HCl}$ combination is used to treat high blood sugar levels that are caused by a type of diabetes mellitus or sugar diabetes called Type 2 diabetes. Normally, after the food intake, pancreas releases insulin to help the body to store excess sugar for later use. This process occurs during normal digestion of food. In Type 2 diabetes, body does not work properly to store the excess sugar and the sugar remains in the bloodstream. Chronic high blood sugar can lead to serious health problems in the future. With two actions, the combination of glipizide and metformin $\mathrm{HCl}$ helps body to cope with high blood sugar [2]. Glipizide stimulates the release of insulin from the pancreas, directing the body to store blood sugar. Metformin $\mathrm{HCl}$ has three different actions: It slows the absorption of sugar in small intestine; it also stops the liver from converting stored sugar into blood sugar and it helps body to use natural insulin more efficiently [6-11]. In diabetic patient, the absorption of glipizide is erratic because of impaired gastric function and motility. To overcome these drawbacks glipizide will be formulated as gastro-retentive drug delivery system (GRDDS).

The main aim to develop the metformin $\mathrm{HCl}$ as GRDDS, which not only releases the drug in the absorption window but also provides controlled release drug profile, that may result patient compliance and therapeutic success. The main objective of this work is to formulate and evaluate floating tablets of metformin $\mathrm{HCl}$ and glipizide.

\section{METHODS}

Glipizide, metformin $\mathrm{HCl}$, hydroxypropyl methylcellulose (HPMC) (K100M and K4M) was gifted from Yarrow Chemicals Ltd., Mumbai and polyvinylpyrrolidone (PVP) K25 gifted from SDFCL Mumbai.

\section{Methods}

Preparation of GD and $\mathrm{MHCl}$ gastroretentive tablet by wet granulation method

Accurately weighed out all materials according to the formula (Table 1) and shift the material through 80 number mesh. Mixed the drug, polymer and citric acid by geometrical mixing in a double polybag for 10 minutes. To this mixture added sodium bicarbonate as a gas generating agent. Again mixed for 5 minutes. The mixture was granulated using PVP K25 by dissolved in sufficient isopropyl alcohol and passed through sieve number 12 . Granules were air dried and were passed through sieve number 20 . To the dried granules magnesium stearate and talc were added and it is further mixed in a blender.

\section{Formulation}

Angle of repose

The angle of repose of powder was determined by the funnel method using formula [3] (Table 2):

$\operatorname{Tan} \theta=\mathrm{h} / \mathrm{r}$

$\theta=\operatorname{Tan}-1 \mathrm{~h} / \mathrm{r}$

$\mathrm{h}=$ Height of the pile, $\mathrm{r}=$ Radius of the pile.

\section{Bulk density}

The apparent bulk density in $\mathrm{g} / \mathrm{ml}$ was calculated using the formula [4]:

Bulk density=weight of powder/bulk volume. 
Table 1: Formula for gastroretentenive tablet

\begin{tabular}{|c|c|c|c|c|c|c|c|c|c|}
\hline FC & GD (mg) & MHCl (mg) & HРMC К100M & HPMC K4M & PVP K25 (mg) & Citric acid & $\mathrm{NaHCO}_{3}(\mathrm{mg})$ & Mg stearate (mg) & Talc (mg) \\
\hline F1 & 5 & 500 & - & 100 & 30 & 50 & 90 & 5 & 5 \\
\hline F2 & 5 & 500 & 60 & 40 & 30 & 50 & 90 & 5 & 5 \\
\hline F3 & 5 & 500 & 100 & - & 30 & 50 & 90 & 5 & 5 \\
\hline F4 & 5 & 500 & 20 & 85 & 30 & 50 & 85 & 5 & 5 \\
\hline F5 & 5 & 500 & 40 & 60 & 30 & 50 & 90 & 5 & 5 \\
\hline F6 & 5 & 500 & 50 & 50 & 30 & 60 & 80 & 5 & 5 \\
\hline F7 & 5 & 500 & 100 & - & 30 & 55 & 85 & 5 & 5 \\
\hline
\end{tabular}

FC: Fenoprofen calcium, HPMC: Hydroxypropyl methylcellulose, PVP: Polyvinylpyrrolidone

Tap density

Tap density was determined by 500 tap method. Tapped density was calculated using the formula [4]

Tap density=weight of powder/tapped volume.

\section{Carr's index (\%)}

The powder blend ( $5 \mathrm{~g}$ ) was weighed and was transferred to a measuring cylinder, and then it was subjected to 100 tappings. The tapped density and poured density were noted (Table 3 ).

Carr's index was calculated by the following formula [3]:

Carr's index $(\%)=($ tap density-bulk density $) /$ tap density $\times 100$.

Hausner's ratio

Hauser's ratio was calculated by the following formulae [3]:

Hausner's ratio=tapped density/bulk density.

\section{Compression of tablet}

Tablets were compressed on a degree of substitution- $16 \mathrm{~mm}$ punch using multistation tablet punching machine punch with flat surface and round shape.

\section{Postcompression parameters}

\section{Weight variation}

The weight variation test was carried out to determine to what extent the weight of an individual tablets deviates with respect to the average tablet tested. To calculate the weight variation, 20 tablets at random were weighed and then the average weight was noted. Then, the weight deviation and percentage deviation were calculated [3] (Table 4).

\section{Hardness}

Five tablets were randomly picked from each formulation, and the mean hardness was determined using Monsanto hardness tester [3,12-14].

\section{Thickness}

About 10 tablets were selected randomly and thickness was measured using vernier caliper scale, which permits accurate measurement [3,12-14].

\section{Friability}

A minimum of 40 tablets were randomly selected and the total weight was noted. The weighed tablets were placed in the Roche friabilator and allowed to make 100 revolutions at the rate of $25 \mathrm{rpm}$ for 4 minutes. The tablets were dusted and weighed again. The $\%$ friability was calculated using the formula $[3,15,16]$.

$\%$ Friability $=\frac{\text { Initial weight-final weight }}{\text { Initial weight }} \times 100$

\section{Disintegration time}

Tablet disintegration is an important step in drug absorption. The test for disintegration was carried out in electro lab United States
Table 2: Effect of angle of repose on flow property

\begin{tabular}{ll}
\hline Angle of repose $(\boldsymbol{\theta})$ & Type of flow \\
\hline$<20$ & Excellent \\
$20-30$ & Good \\
$30-34$ & Passable \\
$>40$ & Very poor \\
\hline
\end{tabular}

Table 3: Relation between \% compressibility and flowability

\begin{tabular}{ll}
\hline \% Compressibility & Flowability \\
\hline $5-15$ & Excellent \\
$12-16$ & Good \\
$18-21$ & Fair to passable \\
$23-35$ & Poor \\
$33-38$ & Very poor \\
$>40$ & Extremely poor \\
\hline
\end{tabular}

Table 4: Weight variation for uncoated tablets

\begin{tabular}{ll}
\hline Average weight & Maximum \% difference allowed \\
\hline$<80$ & 10 \\
$80-324$ & 7.5 \\
$>324$ & 5 \\
\hline
\end{tabular}

Pharmacopoeia (USP) disintegration test apparatus. To test the disintegration time of tablets, one tablet was placed in each tube, and the basket rack was positioned in a $1 \mathrm{~L}$ beaker containing $0.1 \mathrm{~N} \mathrm{HCl}$ buffer solution at $37^{\circ} \mathrm{C} \pm 1^{\circ} \mathrm{C}$ such that the tablet remains $2.5 \mathrm{~cm}$ below the surface of the liquid. The time taken for the complete disintegration of the tablets was noted [3].

\section{Drug content uniformity}

About 10 tablets were randomly selected and crushed. Then, these tablets were dissolved in a small quantity of methanol and the volume was made up to $100 \mathrm{ml}$ with $0.1 \mathrm{~N} \mathrm{HCl}$. The solution was then filtered and the absorbance was measured at $275.80 \mathrm{~nm}$ and $259.60 \mathrm{~nm}$, respectively, using $0.1 \mathrm{~N} \mathrm{HCl}$ as a blank. The test results were interpreted with the limits of British pharmacopoeia $[3,17,18]$.

\section{In vitro drug release study}

In vitro drug release study was performed using USP Type II dissolution apparatus. $0.1 \mathrm{~N} \mathrm{HCl}(900 \mathrm{ml})$ maintained at a temperature of $37^{\circ} \mathrm{C} \pm 0.5^{\circ} \mathrm{C}$ as dissolution medium. The RPM was maintained at 50 . The absorbance was taken at the $\lambda_{\max }$ of GD $(275.80 \mathrm{~nm})$ and at the isoabsorptive point of two drugs (259.5 nm) using UV spectrophotometer [5].

\section{Drug release kinetic data analysis}

To describe the kinetics of the release process of drug in the different formulations, models were fitted to the dissolution data of optimized formulations using linear regression analysis.

\section{Zero order kinetics}

To study the zero order release rate kinetics, the release rate data were fitted to the following equation. 


$$
\mathrm{Q}_{\mathrm{t}}=\mathrm{Q}_{0}+\mathrm{K}_{0} \mathrm{t}
$$

Where, $Q_{t}=$ amount of drug dissolved in time $t$

$\mathrm{Q}_{0}=$ initial amount of drug in the solution

$\mathrm{K}_{0}=$ zero order release constant.

First order kinetics

To study the first order release rate kinetics the release rate data were fitted to the following equation:

$\log Q_{t}=\log Q_{0}+K_{1} t / 2.303$

Where, $Q_{t}=$ amount of drug released in time $t$

$\mathrm{Q}_{0}=$ initial amount of drug in the solution

$\mathrm{K}_{1}$ =first order release constant.

\section{Higuchi model}

Mathematical expressions were obtained for drug particles dispersed in a uniform matrix behaving as the diffusion media, the equation is:

$Q_{t}=K_{h}+1 / 2$

Where, $Q_{t}=$ amount of drug released in time $t$

$\mathrm{K}_{\mathrm{h}}$ =Higuchi dissolution constant.

\section{Korsmeyer and Peppas model}

This model is generally used to analyze the release of pharmaceutical polymeric dosage forms, when the release mechanism is not well known or when more than one type of release phenomena could be involved:

$\mathrm{Mt} / \mathrm{M} \infty=\mathrm{K}_{\mathrm{tn}}$

Where Mt/Mœ=fraction of drug release

$\mathrm{K}=$ release constant

$\mathrm{t}=$ release time

$\mathrm{n}=$ dissolution exponent for the drug release that is dependent on the slope of the matrix dosage form.

If the exponent $n=0.5$ or near, then the drug release mechanism is Fickian diffusion and if $\mathrm{n}$ have value near 1.0, then it is non-Fickian diffusion (Table 5).

The results obtained from in vitro drug release studies were plotted adopting five different mathematical models of data treatment as follows:

- Cumulative percent drug release versus time (zero order rate kinetics)

- $\quad$ Log cumulative percent drug retained versus time (first order rate kinetics)

- Higuchi classical diffusion equation (Higuchi matrix)

- $\quad$ Log of cumulative percent drug release versus log time (Peppas equation)

\section{Stability studies}

The stability testing was done by exposing the prepared tablets to temperature and humidity according to the ICH guidelines for a period of 6 -month. The conditions were $40^{\circ} \mathrm{C} \pm 2^{\circ} \mathrm{C} / 75 \% \pm 5 \%$ relative humidity $(\mathrm{RH})$ and stability studies were carried out for initial 3 months and 6 months. At the end of the 6 months hardness, friability, disintegration, and drug content evaluation were performed [19,20,21].

Table 5: "n" values for Korsmeyer and Peppas model

\begin{tabular}{ll}
\hline Release exponent & Drug transport mechanism \\
\hline $\mathrm{n}=0.5$ & $\begin{array}{l}\text { Fickian diffusion or square root of } \\
\text { time kinetics }\end{array}$ \\
$0.5<\mathrm{n}<1$ & Anomalous (non-Fickian diffusion) \\
$\mathrm{n}=1$ & Case II transport \\
$\mathrm{n}>1$ & Super case II transport \\
\hline
\end{tabular}

\section{RESULTS AND DISCUSSION}

\section{Preformulation studies}

The identification of the drug done by Fourier transform infrared is similar to that of reference. Compatibility study concludes that there is no interation between the drug and polymer.

\section{Evaluation of floating tablet}

Pre-compression parameters

Precompression parameters of the formulation such as Angle of repose, Bulk density, Porosity and Compressibility index are discussed in Table 6.
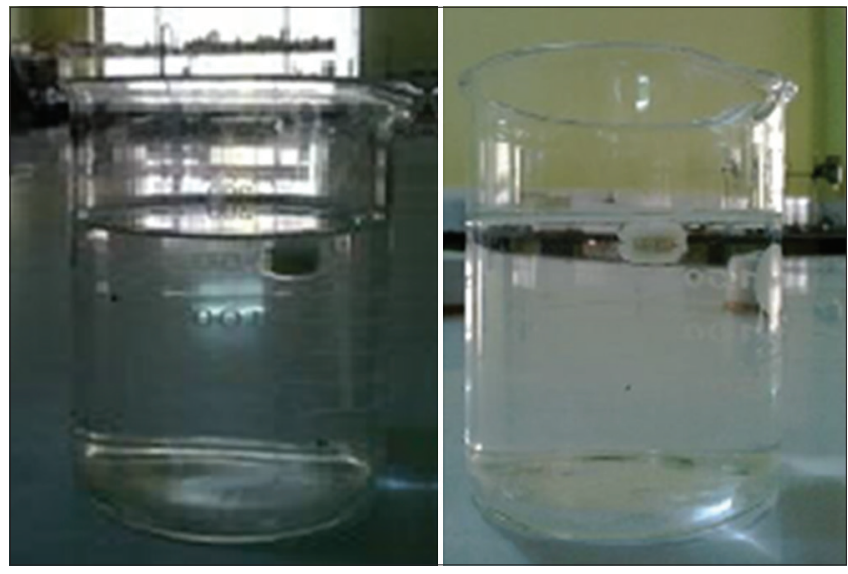

Fig. 1: Floating of formulation

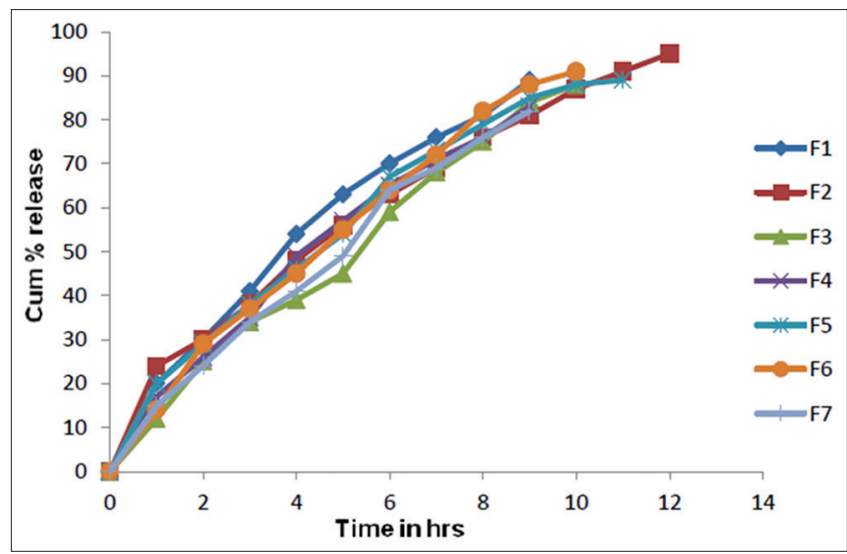

Fig. 2: Swelling index of all formulation

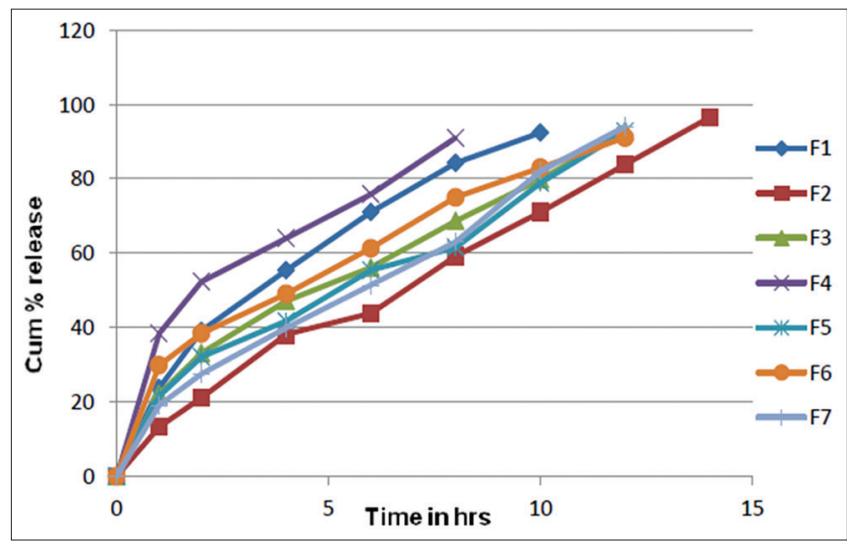

Fig. 3: In vitro release of all formulations 
Table 6: Angle of repose, bulk density, porosity and compressibility index

\begin{tabular}{|c|c|c|c|c|c|c|}
\hline FC & Angle of repose $(\theta)$ & $\begin{array}{l}\text { Bulk density } \\
(\mathrm{g} / \mathrm{ml})\end{array}$ & $\begin{array}{l}\text { Tapped density } \\
(\mathrm{g} / \mathrm{ml})\end{array}$ & $\begin{array}{l}\text { Carrs index } \\
(\%)\end{array}$ & Hausners ratio & $\begin{array}{l}\text { Compressibility index } \\
(\%)\end{array}$ \\
\hline F1 & $32^{\circ} 15^{\prime}$ & 0.492 & 0.685 & 28.18 & 1.39 & 13.14 \\
\hline F2 & $28^{\circ} 48^{\prime}$ & 0.522 & 0.711 & 26.58 & 1.36 & 12.30 \\
\hline F3 & $33^{\circ} 13^{\prime}$ & 0.445 & 0.720 & 38.19 & 1.62 & 15.90 \\
\hline F4 & $25^{\circ} 28^{\prime}$ & 0.588 & 0.657 & 10.50 & 1.12 & 15.35 \\
\hline F5 & $28^{\circ} 73^{\prime}$ & 0.470 & 0.685 & 31.39 & 1.46 & 12.57 \\
\hline F6 & $29^{\circ} 93^{\prime}$ & 0.481 & 0.633 & 24.01 & 1.32 & 14.37 \\
\hline
\end{tabular}

FC: Fenoprofen calcium

Table 7: Physicochemical parameters of core tablet

\begin{tabular}{lllll}
\hline Formulation & Thickness (mm) & Diameter (mm) & Hardness (kg/cm $)^{2}$ & Friability (\%) \\
\hline F1 & $5.91 \pm 0.001$ & 10.2 & 6.0 & 0.651 \\
F2 & $5.65 \pm 0.004$ & 10.2 & 6.0 & 0.431 \\
F3 & $5.56 \pm 0.005$ & 10.4 & 5.5 & 0.521 \\
F4 & $5.61 \pm 0.004$ & 10.1 & 5.2 & 0.473 \\
F5 & $5.45 \pm 0.003$ & 10.4 & 6.0 & 0.417 \\
F6 & $5.38 \pm 0.004$ & 10.4 & 5.5 & 0.554 \\
F7 & $5.65 \pm 0.003$ & 10.1 & 5.6 & 0.661 \\
\hline
\end{tabular}

FC: Fenoprofen calcium

\section{Post-compression parameters}

All formulations remained white, smooth, flat faced circular with no visible cracks. The results are shown in Table 7. All the formulations showed values within the prescribed limits for tests like hardness, friability, and weight variation which indicate that the prepared tablets are of good standard quality

\section{Content uniformity}

The $\%$ amounts of drug content of the different formulations have been shown in Table 8. The \% amounts of drug content of all formulations were found to be in the range of $98.19-103.07 \%$, i.e., within $\pm 5 \%$ limit.

\section{Buoyancy evaluation}

All the formulations were found to be floating in the release medium chosen as long as the study was conducted (Table 9). The buoyancy might have resulted due to the polymers chosen (low density) and the $\mathrm{CO}_{2}$ liberated by the sodium bicarbonate after the interaction with $\mathrm{HCl}$.

\section{Swelling index}

The swelling index of floating tablets of F1-F7 is shown in Fig. 2. HPMC K4M and HPMC K100M (F6, F7) swelled rapidly at the beginning in $0.1 \mathrm{~N} \mathrm{HCl}$. Tablets containing combination of HPMC K4M and HPMC (F2) showed constant increasing in swelling index up to $12 \mathrm{hrs}$. The combination of HPMC K4M and HPMC K100M resulted in a higher swelling index compared with HPMC K100M alone. The HPMC grade also affects the swelling and hydration with considerably higher swelling index for HPMC K100M than HPMC K4M. HPMC K4M exhibited lower swelling index, but there was no decrease in swelling rate.

\section{In vitro dissolution study}

The in-vitro dissolution of gastric-oral floating tablets was carried out in $0.1 \mathrm{~N} \mathrm{HCl}$ medium. In vitro release profile of GD and $\mathrm{MHCl}$ from the floating tablet was examined in $0.1 \mathrm{~N} \mathrm{HCl}$ for $14 \mathrm{hr}$. All the tablets were prepared by effervescent approach (Figure 3).

\section{Model plot of GRDDS released from formulation}

In the kinetic release the zero order, first order, Higuchi model and Krosmeyer-Peppas model and the values the ' $n$ ' values is within the limit. The Krosmeyer-Peppas equation suggested that, all the formulation showed drug release by non-fickian diffusion mechanism. From the obtained results (Figs. 4-11) the floating tablet of GD and $\mathrm{MHCl}$ may increase the bioavailability.
Table 8: Results of content uniformity test

\begin{tabular}{ll}
\hline Formulations & \% amount of drug content \\
\hline F1 & 98.19 \\
F2 & 99.60 \\
F3 & 101.06 \\
F4 & 98.65 \\
F5 & 102.12 \\
F6 & 99.01 \\
F7 & 103.07 \\
\hline
\end{tabular}

Table 9: Results of FLT and total floating time

\begin{tabular}{lll}
\hline FC & FLT (seconds) & Total floating time (hrs) \\
\hline F1 & 54 & $>10$ \\
F2 & 45 & $>12$ \\
F3 & 85 & $>12$ \\
F4 & 45 & $>14$ \\
F5 & 62 & $>12$ \\
F6 & 125 & $>12$ \\
F7 & 130 & $>12$ \\
\hline
\end{tabular}

FLT: Floating lag time

Table 10: Release kinetic profile of different formulations

\begin{tabular}{|c|c|c|c|c|c|}
\hline \multirow[t]{2}{*}{ FC } & \multirow{2}{*}{$\begin{array}{l}\text { Zero order } \\
\text { r2 }\end{array}$} & \multirow{2}{*}{$\frac{\text { First order }}{\text { r2 }}$} & \multirow{2}{*}{$\begin{array}{l}\text { Higuchi } \\
\text { r2 }\end{array}$} & \multicolumn{2}{|c|}{ Korsmeyer-Peppas } \\
\hline & & & & r2 & $\mathbf{n}$ \\
\hline F1 & 0.8595 & 0.9813 & 0.9957 & 0.5892 & 0.49 \\
\hline $\mathrm{F} 2$ & 0.9954 & 0.8358 & 0.9471 & 0.7507 & 0.47 \\
\hline F3 & 0.9594 & 0.9174 & 0.9891 & 0.6115 & 0.49 \\
\hline $\mathrm{F} 4$ & 0.8595 & 0.9534 & 0.9869 & 0.4609 & 0.51 \\
\hline F5 & 0.9647 & 0.8861 & 0.9734 & 0.6146 & 0.48 \\
\hline F6 & 0.9238 & 0.9725 & 0.9948 & 0.5487 & 0.46 \\
\hline F7 & 0.9827 & 0.8804 & 0.9614 & 0.6561 & 0.49 \\
\hline
\end{tabular}

Kinetic values obtained from different plots of formulation

The cumulative percentage of drug release as a function square root of time (Higuchi plot) was linear and it suggested that the release of GD and $\mathrm{MHCl}$, HPMC K100M, and HPMC K4M was diffusion controlled. The $\mathrm{n}$ values obtained from the Peppas-Korsmeyer equation suggested that all the formulation showed drug release 


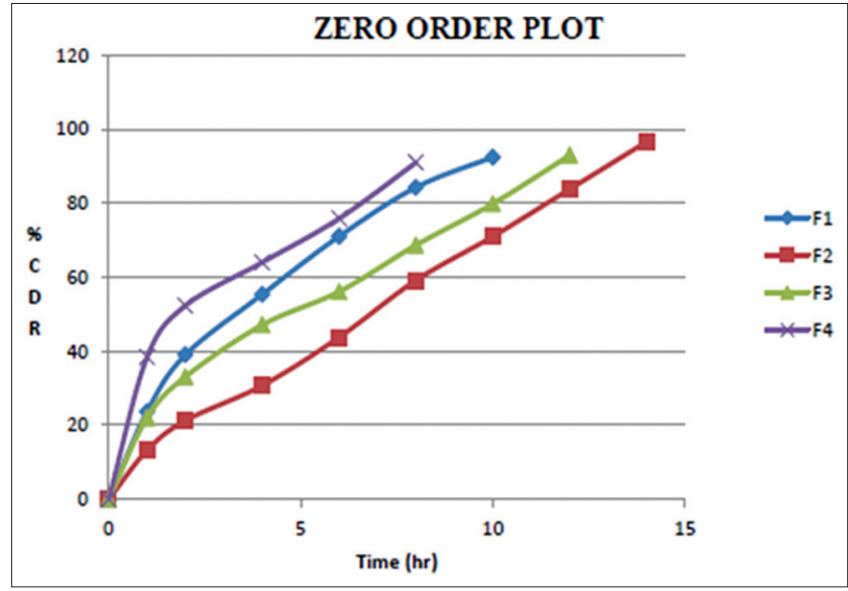

Fig. 4: Zero order plot for F1, F2, F3 and F4

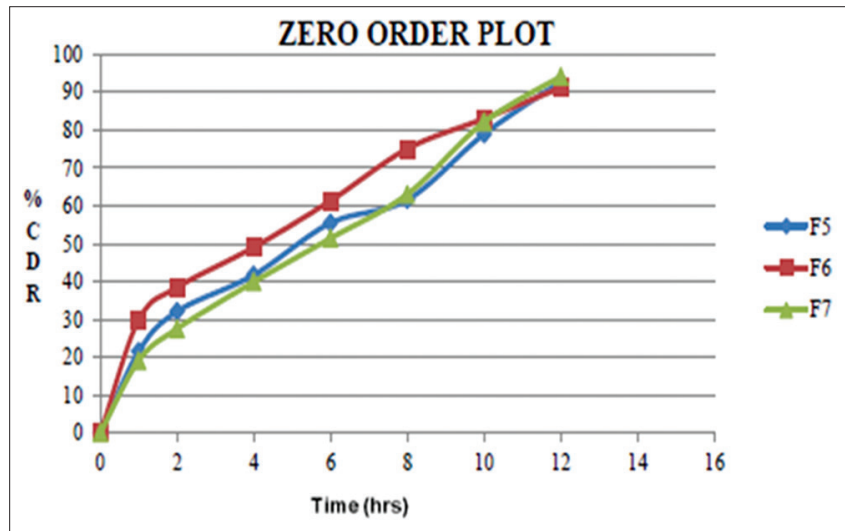

Fig. 5: Zero order plot for F5, F6 and F7

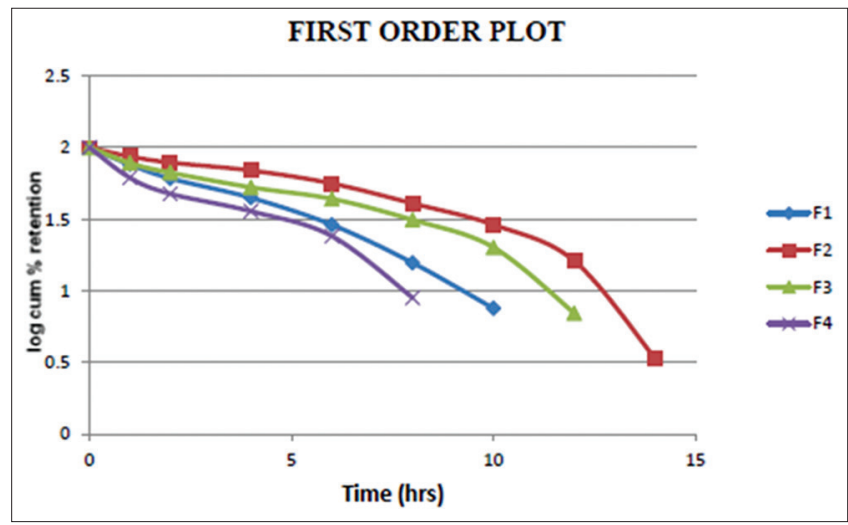

Fig. 6: First order plot for F1, F2, F3 and F4

by non-Fickian diffusion mechanism. From the above results, the floating tablet of GD and $\mathrm{MHCl}$ may increase the bioavailability with once daily dosage form.

Stability study parameters of formulation

Stability study of formulation F2

The optimized floating tablets were selected for stability study on the basis of in vitro buoyancy and in vitro drug dissolution studies. The tablets were investigated at $40^{\circ} \mathrm{C} / 75 \% \mathrm{RH}$ for 6 months. From the data, the formulation is found to be stable under the conditions mentioned above since there was no significant change in the percentage amount of drug content. Thus, it was found that the floating tablets of $\mathrm{MHCl}$ and GD were stable under these storage conditions for at least 6 months.

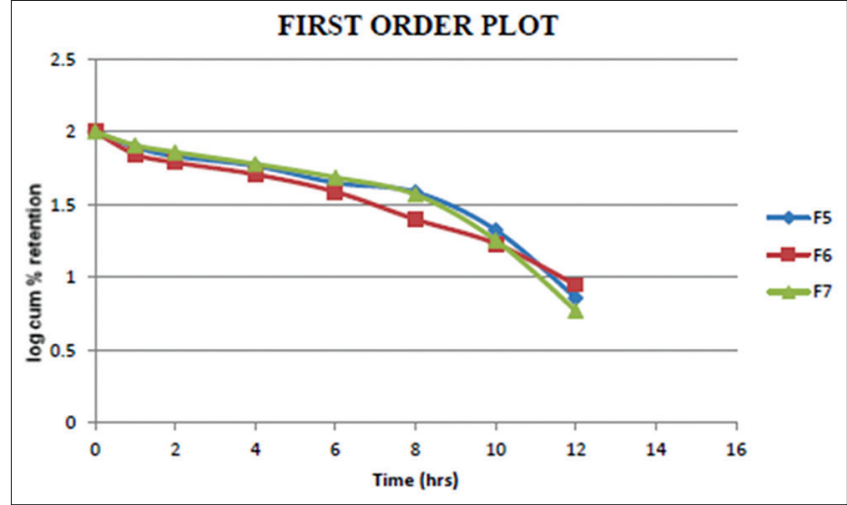

Fig. 7: First order plot for F5, F6 and F7

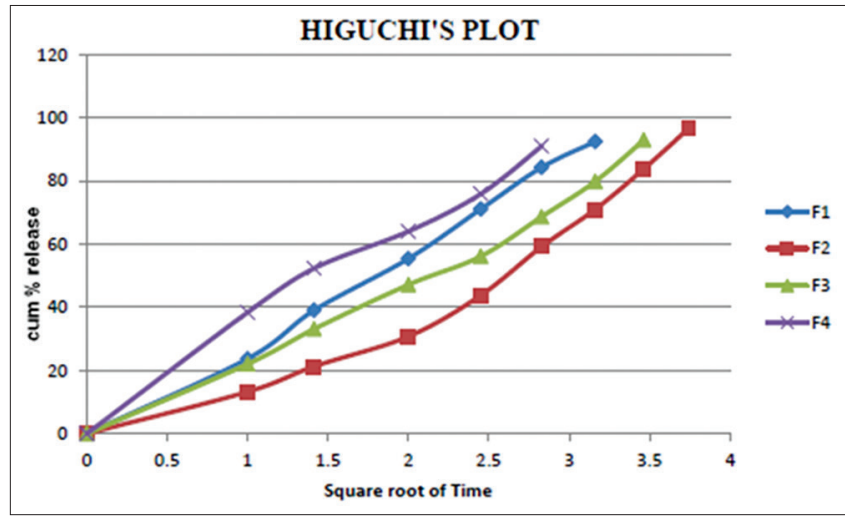

Fig. 8: Higuchi's plot for F1, F2, F3 and F4

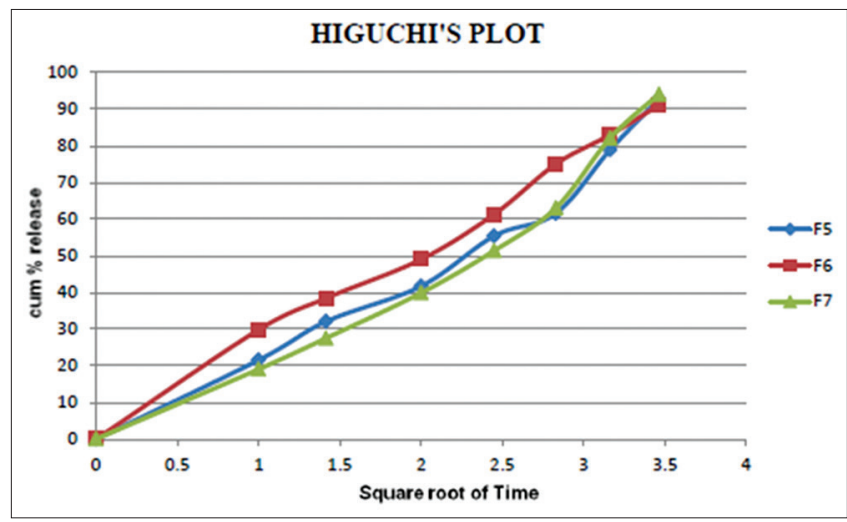

Fig. 9: Higuhi's plot for F5, F6 and F7

\section{CONCLUSION}

The present investigation of tablet form of gastric oral floating controlled drug delivery of $\mathrm{GD}$ and $\mathrm{MHCl}$ is prepared using the retardant,

Table 11: Stability study parameters of formulation F2

\begin{tabular}{llll}
\hline Evaluation parameters & Initially & $\begin{array}{l}\text { After 3 } \\
\text { months }\end{array}$ & $\begin{array}{l}\text { After 6 } \\
\text { months }\end{array}$ \\
\hline Weight variation (\%) & 1.02 & 1.02 & 1.02 \\
Hardness & 6.0 & 6.0 & 6.0 \\
Friability (\%) & 0.431 & 0.452 & 0.452 \\
Floating lag time (seconds) & 45 & 45 & 45 \\
$\begin{array}{l}\text { In vitro dissolution study } \\
\text { (after 14 hrs) (\%) }\end{array}$ & 96.63 & 96.45 & 96.39 \\
\hline
\end{tabular}




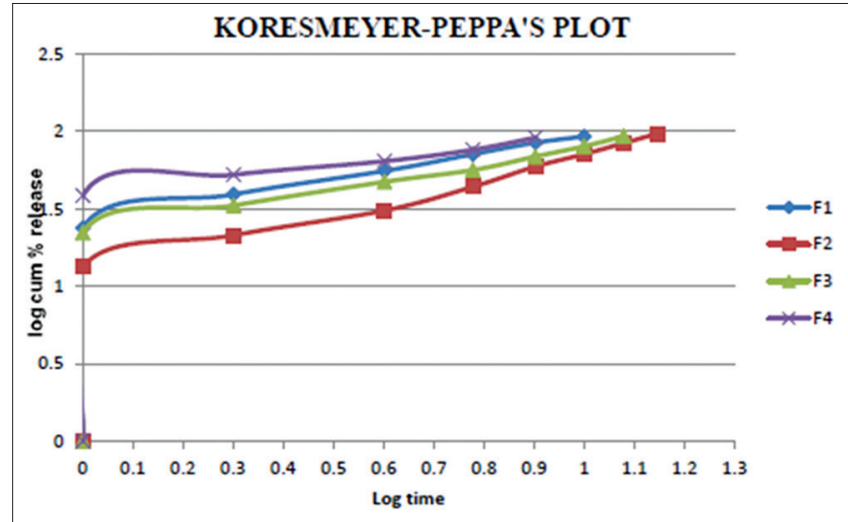

Fig. 10: Korsmeyer-Peppas plot for F1, F2, F3 and F4

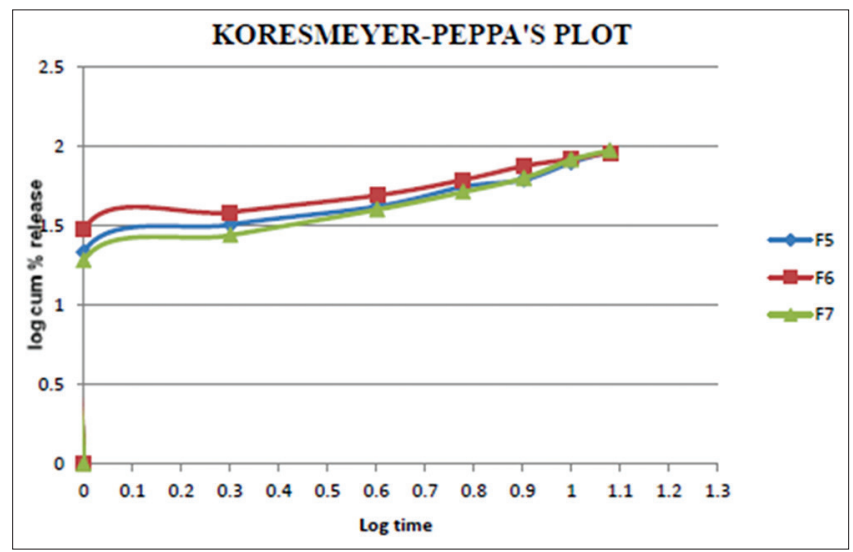

Fig. 11: Korsmeyer-Peppas plot for F5, F6 and F7

alkalizing and solubilizing agent, proved to be an ideal formulation as it released the drug in controlled fashion for extended period of time by maintaining the buoyancy. Controlled release floating drug delivery of $\mathrm{GD}$ and $\mathrm{MHCl}$ showed sufficient release for extended period of time. As a result, the frequent dosing and possible incomplete absorption of drug can be avoided. The in vitro drug release profiles obtained for tablets (F2) made with combinations of HPMC K4M, HPMC, and K100M showed lesser floating lag time ( $<60$ seconds) and a prolonged floating duration ( $>14 \mathrm{hrs}$ ) with controlled and sustained release of $\mathrm{MHCl}$ and GD.

\section{ACKNOWLEDGMENT}

Authors extend gratitude to yarrow chemicals and SDFCL Mumbai for gifting the drug and chemicals. Also acknowledge to Shree Devi College of Pharmacy, Mangalore.

\section{REFERENCES}

1. Nayak AK, Maji R, Das B. Gastroretentive drug delivery system. Asian J Pharm Clin Res 2010;3(1):1-2.
2. Raja BD, Thakkar HR, Paramasivam S, Jamsheer AK, Adimoolam S. Formulation and evalution of gastroretentive floating tablets of glipizide. Int J Res Ayur Pharm 2011;2(3):911-7.

3. Dave BS, Amin AF, Patel MM. Gastroretentive drug delivery system of ranitidine hydrochloride: Formulation and in vitro evaluation. AAPS Pharm Sci Tech 2004;5(2):e34.

4. Prajapati ST, Patel LD, Patel DM. Studies on formulation and in vitro evaluation of floating matrix tablets of domperidone. Indian J Pharm Sci 2009;71(1):19-23.

5. Gohel MC, Mehta PR, Dave RK, Bariya NH. More relevant dissolution method for evalution of floating drug delivery system. Dissol Techno 2005;22-5.

6. Joseph NJ, Lakshmi S, Jayakrishnan A. A floating-type oral dosage form for piroxicam based on hollow polycarbonate microspheres: In vitro and in vivo evaluation in rabbits. J Control Release 2002;79(1-3):71-9

7. Gohel MC, Mehta PR, Dave KR. A more relevant method for evaluation of floating drug delivery system. Dissol Technol 2004;22:5.

8. Vedha HB, Brahma RA, Samyuktha RB. Floating drug delivery of nevirapine as a gastroretentive system. J Young Pharm 2010;2(4):350-5.

9. Available from: http//www.slideboom.com/presentation/288556/ Methods to evaluate the compability of drug with exipients. [Last accessed on 2015 Feb 02].

10. Kulkarni AP, Jaiswal M, Jawale BS, Shirolkar SV, Kasture PV. Development and evaluation of press-coated tablets for chronotherapeutical drug delivery using gellable and permeable polymer. Der Pharma Lett 2010;2(4):482-97.

11. Government of India, Ministry of Health and Family Welfare. Indian Pharmacopeia. Vol.2. Ghaziabad: The Indian Pharmacopoeia Commission; 1996. p. 659-61.

12. El-Kamel AH, Sokar MS, Al Gamal SS, Naggar VF. Preparation and evaluation of ketoprofen floating oral delivery system. Int J Pharm 2001;220(1-2):13-21

13. Basak SC, Rahman J, Ramalingam M. Design and in vitro testing of a floatable gastroretentive tablet of metformin hydrochloride. Pharmazie 2007;62(2):145-8.

14. Hui M, Ozkan Y. Bilayer buoyant tablet consisting one immediate release layer and one sustained release layer. Drug Dev Ind Pharm 2000;26(8):857-66.

15. Wu W, Zhou Q, Zhang HB, Ma GD, Fu CD. Studies on nimodipine sustained-release tablet capable of floating on gastric fluid with prolonged gastric resident time. Yao Xue Xue Bao 1997;32(10):786-90.

16. Moursy NM, Afifi NN, Ghorab DM, El-Saharty Y. Formulation and evaluation of sustained release floating capsules of nicardipine hydrochloride. Pharmazie 2003;58(1):38-43.

17. Hou SY, Cowles VE, Berner B. Gastric retentive dosage forms: A review. Crit Rev Ther Drug Carrier Syst 2003;20(6):459-97.

18. Steingoetter A, Kunz P, Weishaupt D, Mäder K, Lengsfeld $\mathrm{H}$, Thumshirn $\mathrm{M}$, et al. Analysis of the meal-dependent intragastric performance of a gastric - retentive tablet assessed by magnetic resonance imaging. Aliment Pharmacol Ther 2003;18(7):713-20.

19. The European Agency for the Evaluation of Medical Products, ICH Topic Q2B Note for Guidance on Validation of Analytical Procedures: Methodology GPMP/ICH/281/95. Geneva, Switzerland: IFPMA; 1996. p. 1-8.

20. Umamaheswari RB, Jain S, Tripathi PK, Agrawal GP, Jain NK Floating-bioadhesive microspheres containing acetohydroxamic acid for clearance of Helicobacter pylori. Drug Deliv 2002;9(4):223-31

21. Nur AO, Zhang JS. Captopril floating and/or bioadhesive tablets: Design and release kinetics. Drug Dev Ind Pharm 2000;26(9):965-9. 